\title{
Teacher Educator-Embedded Professional Learning Model
}

\author{
Scott A. Courtney ${ }^{1 *}$
}

\author{
${ }^{1}$ Kent State University, USA \\ *CORRESPONDENCE: $\square$ scourtn5@kent.edu
}

\begin{abstract}
The author describes interactions with two middle grades (grades 6-8, student ages 11-14 years) and three secondary school (grades 9-12, student ages 14-18 years) mathematics teachers designed to increase and enhance teachers' content knowledge and transform their classroom instruction by embedding the author (i.e., mathematics teacher educator) into teachers' practices. In addition, the author operationalizes the teacher educator-embedded professional learning model. Embedding a teacher educator into grade K-12 (student ages 5-18 years) teachers' practices, as presented in this study, involves more than simply implementing lessons with teachers. Rather, the mathematics teacher educator navigates iterative instructional cycles alongside the participating teacher, serving as sounding board, interventionist, epistemic student, and colleague. Results of teacher-educator embedding are presented, indicating participating teachers increased their content knowledge, engaged their students in more rigorous mathematics, demonstrated increased self-efficacy and more frequently engaged students in mathematical sense making, reasoning, modelling, generalizing, and communicating.
\end{abstract}

Keywords: mathematics teacher education, professional learning, teacher educator-embedding

\section{INTRODUCTION}

\section{Background}

Over the past 25 years, research in teacher education and teacher change has identified characteristics of high quality professional development (e.g., Clarke, 1994; Guskey \& Yoon, 2009; Loucks-Horsley, Stiles, Mundry, Love, \& Hewson, 2010). Such characteristics include professional development that is sustained, intensive, fosters collaboration, models desired classroom approaches, and provides a degree of choice for participating teachers. Furthermore, research has shown the content focus of professional development should be challenging, grounded in student learning, and situated in the work of participating teachers' own practices (Darling-Hammond \& McLaughlin, 1995; Ingvarson, 2005).

In the U.S., the Common Core State Standards for Mathematics (CCSSM) (National Governors Association Center for Best Practices \& Council of Chief State School Officers [NGA Center \& CCSSO], 2010) and other college and career readiness mathematics state standards (e.g., Nebraska's College and Career Ready Standards for Mathematics) have provided teacher educators and professional development facilitators expanded opportunities to engage with practicing mathematics teachers. Such standards not only provide coherence and rigor regarding content, but also focus on providing students with opportunities to engage in mathematical sense making, reasoning, modelling, generalizing, and communicating. According to Sztajn, Marrongelle, and Smith (2011) these standards represent "a significant departure from what mathematics is currently taught in most classrooms and how it is taught ... [and] are likely to occur only through sustained and focused professional development opportunities for those who teach mathematics" [authors' italics] (p. 3).

Article History: Received 30 April $2018 \bullet$ Revised 23 May $2018 \bullet$ Accepted 26 May 2018

(C) 2018 The Author(s). Open Access terms of the Creative Commons Attribution 4.0 International License (http://creativecommons.org/licenses/by/4.0/) apply. The license permits unrestricted use, distribution, and reproduction in any medium, on the condition that users give exact credit to the original author(s) and the source, provide a link to the Creative Commons license, and indicate if they made any changes. 
In this report, the author describes interactions with two middle grades (grades 6-8, student ages 11-14 years) and three secondary school (grades 9-12, student ages 14-18 years) mathematics teachers designed to increase and enhance teachers' content knowledge and transform their classroom instruction by embedding the author (i.e., mathematics teacher educator) into teachers' practices. This 'embedding' was part of a larger project involving intensive summer workshops and academic year in-person and live synchronous online professional learning sessions. Teacher educator-embedding, as conceptualized here, takes as foundational the assertion "professional knowing is embodied, contextual and embedded in practice; that the change of learning occurs through practice experience and reflective action within contexts that may pose dilemmas" (Webster-Wright, 2009, p. 724). As such, teacher learning is "situated, social and constructed . . . [where] research and support for [professional learning] should reflect these assumptions, or at least acknowledge the difficulties and limitations in researching such experience" (Webster-Wright, 2009, p. 724). In the following sections, the author operationalizes the teacher educator-embedded professional learning model and describes engagements with teachers to address the following research question: How does embedding a mathematics teacher educator in teachers' practices, as co-teacher and colleague, impact participating teachers' content knowledge and instruction?

\section{FRAMEWORK}

The teacher educator-embedded professional learning model is grounded in a constructivist approach to learning mathematics and incorporates notions of: (1) Thompson's (2013, 2016) interpretive framework for the development of powerful Mathematical Meanings for Teaching (MMT); (2) co-teaching (Cook \& Friend, 1995); and (3) iterative cycles of lesson planning, implementation, and reflection aligned with lesson study (Lewis, 2002; Perry \& Lewis, 2009).

\section{Mathematical Meanings for Teaching}

Thompson's framework is developmental and cognitive, involving a Piagetian perspective, where knowledge and meaning are largely synonymous, and both are "grounded in the knower's schemes" (Thompson, 2016, p. 436). According to Thompson (2016), "Teachers' mathematical meanings constitute their images of the mathematics they teach and intend that students have" (p. 437). As such, the mathematical knowledge that matters most for teachers resides in the mathematical meanings teachers' hold (Thompson, 2016). As described in Silverman and Thompson (2008) and Courtney (2017), a teacher's personal and pedagogical understandings each develop via a process Piaget called reflective abstraction-through the construction and reorganization of schemes of meanings, as illustrated in Figure 1.

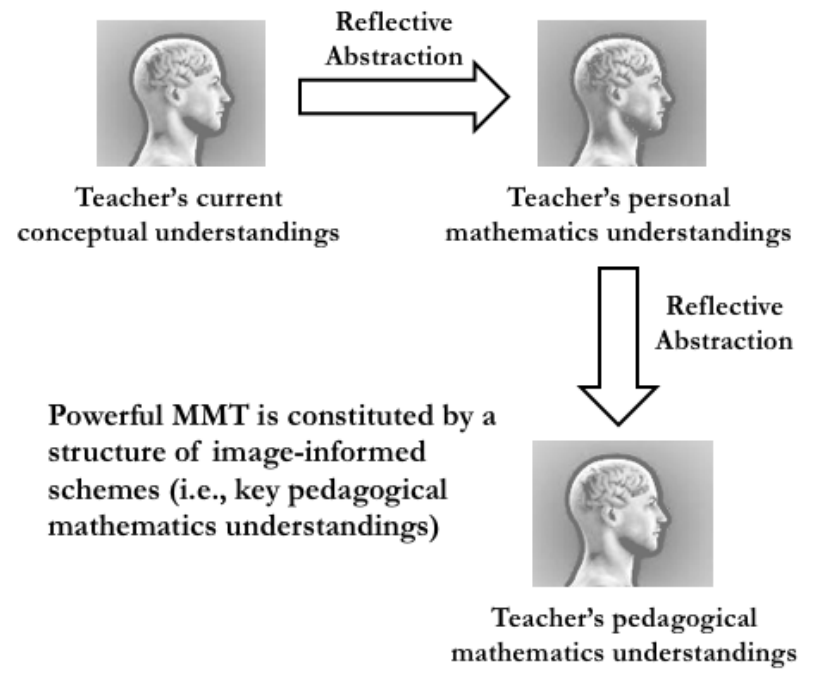

Figure 1. Developing powerful Mathematical Meanings for Teaching

For Thompson (2013), powerful Mathematical Meanings for Teaching (MMT) is constituted by a structure of pedagogically powerful understandings, which orient a teacher's actions to be driven by: (1) an image of a coherent system of ideas and ways of thinking she intends for the students to develop; (2) an image of how these ideas and ways of thinking can develop in a learner; (3) images about what her students might 
understand; (4) an image of ways of knowing that might be problematic to students' understanding; (4) ideas related to materials and activities that promote and support reflective discourse around the desired mathematical ideas which itself might support students developing those ideas; and (5) an image of students' passage through an entire curriculum.

\section{Teacher Educator-Embedded Professional Learning Model}

Embedding a teacher educator into grade K-12 (student ages 5-18 years) teachers' practices involves more than simply implementing lessons with teachers. In the embedded professional learning model described here, the mathematics teacher educator navigates iterative instructional cycles alongside the participating teacher, serving as sounding board, interventionist, epistemic student, and colleague.

Iterative Lesson Cycles. Lesson study has been shown to increase "teacher's opportunities to learn from one another, from practice, and from the curriculum” (Lewis, Perry, Hurd, \& O'Connell, 2006, p. 274). Specifically, teachers engaged in lesson study have demonstrated increased subject matter knowledge, knowledge of instruction, and ability to observe students; and, stronger collegial networks, connection of daily practice to long-term goals, motivation, and sense of efficacy (Lewis, Perry, \& Hurd, 2004, 2009; Taylor, Anderson, Meyer, Wagner, \& West, 2005).

According to Perry and Lewis (2009), the lesson study cycle is comprised of four stages:

[F]ormulate goals for student learning and long-term development; collaboratively plan a 'research lesson' designed to bring to life these goals; conduct the lesson in a classroom, with one team member teaching and others gathering evidence on student learning and development; reflect on and discuss the evidence gathered during the lesson, using it to improve the lesson, the unit, and instruction more generally; and if desired, teach, observe, and improve the lesson again in one or more additional classrooms. (p. 366)

The iterative instructional cycle utilized in the teacher educator-embedded model aligns with lesson study and is also comprised of four stages: goal setting, planning, implementation, and reflection (see Figure 2).

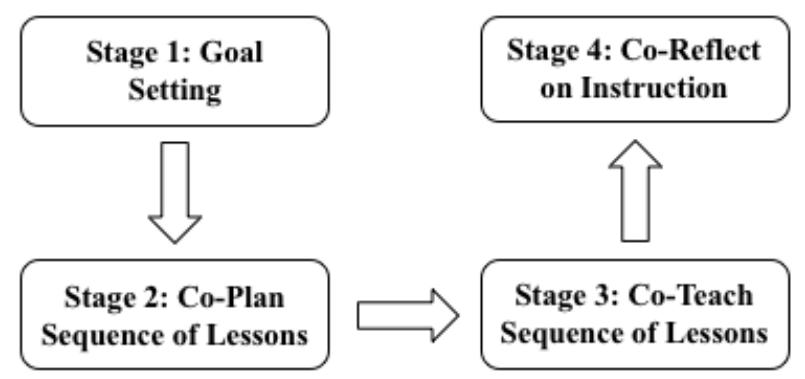

Figure 2. Teacher educator-embedded model of iterative instructional cycles

The instructional cycle is iterative in that teachers maneuver through the four stages at a minimum of four points during the academic year-near the start of the school year, during at least two points across the second and third quarters, and near the end of the school year.

Goal-setting stage. The goal-setting stage involves in-person and live synchronous web meetings between the teacher educator and up to three classroom teachers - teachers who all teach the same grade-level or course. During goal-setting sessions, each participating teacher identifies a topic, a set of mathematics content standards, and mathematical habits of mind to focus on with their students. Classroom teachers teaching different sections of students, perhaps at different buildings or districts, are requested to focus on different content within the grade level or course. The content focus should require a sequence of lessons (typically three to six 50-minute class periods) to introduce, develop, and assess. Teachers should be motivated to choose content that: is new (to the teacher), students typically struggle to understand, the teacher has self-identified as being difficult for her to teach, or the teacher would like to experiment her instruction with (e.g., utilize technology new to the teacher and/or her students, enact as 'flipped' lessons). The requirement that each gradelevel or course teacher focus on different content allows for more content to be addressed in a given iteration, as teachers share their lessons and experiences. Once the participating teacher has identified a topic, set of 
content standards, and mathematical habits of mind she would like to focus on, the teacher and teacher educator co-plan the lessons and co-develop accompanying materials and assessments.

Planning stage. During the planning stage, the participating teacher and teacher educator plan the sequence of lessons as a collaborative team. Although such planning typically involves one classroom teacher working with the teacher educator, it may also involve the teacher educator working with a content teacher and intervention specialist in co-taught classrooms. Throughout the planning stage, the collaborative team rely on: teacher's prior assignments, assessments and notes; textbooks and district generated documents (e.g., pacing guides); state-level standards and documents; and relevant internet resources (e.g., GeoGebra, NRICH Project). If the participating teacher is required to utilize, and perhaps submit to administrators, lesson plans following a specific format or template (e.g., 5E model; Launch, Explore, Summarize), then planning incorporates these demands. Reliance on teacher's existing, familiar, and district- and state-mandated documents situate the work in teacher's own practice and serve to reinforce the notion that teacher's studyrelated work is in support of (not extra to) their practice.

Throughout the planning of a lesson, which may take multiple in-person or live synchronous web meetings (or both), the teacher educator attempts to motivate the participating teacher to make explicit-and objects thought, discussion and subsequent reflection-teacher's hypotheses of their students' knowledge, their theories of mathematics learning and teaching, and teacher's understandings of the mathematics inherent in the lesson, activities and assessments (Simon, 1995; Thompson, 2013). As such, notions of meanings, ways of thinking, and the need for the teacher and her students to articulate their meanings, thinking, and reasoning are consistently addressed (Thompson, 2013, 2016). Although participating teachers create lessons they can utilize, and further modify, in their own classrooms and share with colleagues within and across buildings and districts, lessons are not the main goal of the teacher educator-embedded professional learning model. As with lesson study, the teacher educator-embedded model is "about teacher learning, not just about lessons" (Lewis et al., 2006, p. 274).

Beginning with the end in mind. Although planning relies on participating teacher's existing and mandated documents, to improve or enhance activities and assessments, the teacher educator and participating teacher search for, select, design, or modify material as needed. In addition, the teacher educator manages co-planning to 'begin with the end in mind,' a process based on the habit described by Covey (2004) and aligned with Wiggins and McTighe's (2005) notion of 'backward design.' According to Wiggins and McTighe (2005), backward design "involves thinking a great deal, first, about the specific learning sought, and the evidence of such learnings, before thinking about what we, as the teacher, will do or provide in teaching and learning activities" (p. 14). As such, co-planning in the teacher educator-embedded model initially focuses on developing an assessment task or tasks the classroom teacher and teacher educator believe: (1) faithfully assesses students' development of intended understandings, fluencies, skills, and dispositions; (2) integrates mathematics content and mathematical habits of mind; and (3) supports reflection on the types of instruction that might prepare students to be successful on the assessment task(s). As characterized by Wiggins and McTighe (2005), "We cannot say how to teach for understanding or which material and activities to use until we are quite clear about which specific understandings we are after and what such understandings look like in practice" [authors' italics] (pp. 14-15). Therefore, once the participating teacher and teacher educator have selected, modified, or created an assessment task or tasks to evaluate students' development of the 'selected' mathematics content standards and mathematical habits of mind, they work collaboratively on lessons that will prepare students to be successful on the task(s); these lessons make up the sequence of lessons to be implemented in Stage 3 of the cycle (implementation stage).

Implementation stage. During the implementation stage, the participating teacher and teacher educator co-teach the sequence of lessons. This structure differs from lesson study, where one team member teaches the lesson with remaining team members gathering evidence on student learning and development (Perry \& Lewis, 2009). As with several projects utilizing lesson study (e.g., Fernandez, Cannon, \& Chokshu, 2003; Lewis, Perry \& Hurd, 2009), the teacher educator-embedded model captures each lesson through audio- and video-recordings and student artifacts generated and collected throughout instruction (e.g., student written work).

Co-teaching. Cook and Friend (1995) define co-teaching as "two or more professionals delivering substantive instruction to a diverse, or blended, group of students in a single physical space" (p .1). According to Friend (2008), "Co-teaching presumes that both educators actively participate in the delivery of instruction, share responsibility for all ... students, [and] assume accountability for student learning ... [although] the exact contribution that each person makes may vary" (p. 9). Co-teaching between a general education teacher 
and a specialist has been shown to promote professional growth opportunities, enhance teachers' understandings of curricula, improve the academic performance of students with disabilities, and increase teachers' job satisfaction (Bacharch, Heck \& Dahlberg, 2010; Dieker \& Murawski, 2003; Idol, 2006; Rea, McLaughlin \& Walter-Thomas, 2002; Rice \& Zigmond, 2000). Furthermore, Walsh (2012) asserts, "[C]oteaching has a demonstrated positive effect on student achievement, and that administrators, teachers, and students perceive co-teaching to be socially and academically beneficial to general and special education students" (p. 29).

The notion of co-teachers comprised of teacher educator (or professional facilitator) and classroom teacher, implementing instruction in the teacher's own classroom with her own students is not novel to this study. Bruce, Esmonde, Ross, Dookie, and Beatty (2010) describe a professional learning program in Canada in which professional facilitators co-taught with practicing teachers in teachers' classrooms. According to Bruce et al. (2010), "[S] ustained professional learning programs that are collaborative and classroom-embedded support effective professional learning that leads to substantial student achievement gains and the related gains in teaching quality" (p. 1607). In addition to providing professional learning for participating teachers, the teacher educator-classroom teacher pairing provides opportunities for the teacher educator to experiment with content and explore teacher's and students' understandings, ways of thinking and reasoning, through meaningful interactions with real students in a real classroom.

Reflection stage. During the reflection stage, the teacher educator and classroom teacher co-analyze student work, co-reflect on video of classroom instruction, and discusses potential lesson modifications for subsequent implementation of the lessons (e.g., the following year). According to Rowe (2009), the method of video-stimulated recall "involves video-recording an activity and then replaying the recording to the participants so that they can comment on matters of interest. These matters may be chosen by the researcher or by the participant or ... both" (p. 427). In the teacher educator-embedded model described here, the teacher educator reviews the video-recorded lessons prior to watching it with the classroom teacher; this allows the teacher educator to identify video passages to leverage as didactic objects (Thompson, 2013). Thompson (2013) describes didactic objects as "displays, diagrams, graphs, mathematical expressions, or class activities that ... [are] designed conscientiously to support specific reflective conversations" (p. 77). Therefore, a didactic object is a tool the "teacher [or instructional designer] envisions as having the possibility of engendering productive discourse" (Silverman, 2005, p. 19).

As characterized by Lyle (2003), stimulated recall "is an introspection procedure in which (normally) videotape passages of behaviour are replayed to individuals to stimulate recall of their concurrent cognitive activity" (p. 861). Therefore, stimulated recall "gives participants a chance to view themselves in action as a means to help them recall their thought of events as they occurred" (Nguyen, McFadden, Tangen, \& Beutel, 2013 , p. 2). Throughout Stage 4 of the iterative instructional cycle (reflection stage), the teacher educator manages discussions with each participating teacher-discussions about classroom instruction and student understandings, thinking, and reasoning-around didactic objects (i.e., student work and selected video passages) in hopes the classroom teacher productively reflects on: (1) her own and her students' content knowledge, (2) her instructional practices, (3) her self-efficacy, and (4) her students' capacities to engage in mathematical sense making, reasoning, modeling, generalizing, and communicating.

Two additional constructs play significant roles throughout each iterative instructional cycle: decentration (Piaget, 1962; Steffe \& Thompson, 2000) and cognitive residue (Rosenbaum, 1972; Salomon, Globerson, \& Guterman, 1989). According to Piaget (1962), “[D]ecentering . . . i.e., shifting one's focus and comparing one action with other possible ones, particularly with the actions of other people, leads to an awareness of 'how' and to true operations" (para. 25). As employed throughout the iterative instructional cycle, decentering requires those involved in developing, implementing, and reflecting on instruction (i.e., classroom teacher and teacher educator) to attempt to see mathematical understandings, reasoning, and ways of thinking from students' perspectives.

Finally, as described by Rosenbaum (1972), "Cognitive residues are structures that are absorbed or displaced in development" (p. 471). Furthermore, "Residues become residues because they are not [expressed] ... [and] are displaced or absorbed by new structures which are [expressed] and which, consequently, can become predominant in the cognitive framework" [author's italics] (Rosenbaum, 1972, p. 475). Whereas Rosenbaum (1972) focused on relationships involving cognitive residues and fantasy, Salomon and his colleagues (e.g., Salomon, Globerson, \& Guterman, 1989) conducted several studies focused on the cognitive effects involving student interactions with technology. Salomon, Perkins, and Globerson (1991) distinguish between "two kinds of cognitive effects: Effects with technology obtained during intellectual partnership with 
it, and effects of it in terms of the transferable cognitive residue that this partnership leave behind in the form of better mastery of skills and strategies" [authors' italics] (p. 2). Using Salomon, Perkins, and Globerson's (1991) language, in the teacher-educator-embedded model, iterative instructional cycles are designed to focus on "lasting changes in [teachers'] general cognitive capacities in consequence of interactions with [the activities]" [authors' italics] (p. 3); that is, on the effects of the activities of planning, implementation, and reflection.

\section{METHODS}

The author (i.e., mathematics teacher educator) engaged in the teacher educator-embedded professional learning model with five mathematics teachers. Teachers were a subset of 15 practicing mathematics teachers and intervention specialists from three public school districts in the midwestern United States participating in a Department of Education-funded mathematics and science partnership project. Participation in the project was voluntary and teachers received a modest honorarium. The larger project was designed to provide teachers with opportunities to dig deeply into mathematical ideas within CCSSM (NGA Center \& CCSSO, 2010) and how students come to understand them, improve student learning by enhancing teachers' instruction, and collaboratively plan instruction and assess student learning. Furthermore, project activities were designed to provide teachers with opportunities to reflect on their own activity, both as learners and as teachers. Although all project-participating teachers engaged in intensive summer workshops and academic year in-person and online professional learning sessions, the author will focus on the subset of teachers who participated in the embedded professional learning component of the project.

\section{Participants}

Descriptions of participating teachers discussed in this report and their respective schools and districts are displayed in Table 1. Teacher names are pseudonyms randomly generated using 'average' English first names based on the U.S. Census database (random-name-generator.info, n.d.). District and school names were also randomly generated (FantasyNameGenerators.com, 2018).

Table 1. Teacher, school, and district characteristics for 2016-2017

\begin{tabular}{|c|c|c|c|}
\hline Teacher & Course & School & District \\
\hline $\begin{array}{l}\text { Jeremy } \\
\text { (more than } 10 \\
\text { years of } \\
\text { experience) }\end{array}$ & $\begin{array}{l}\text { High School Algebra } \\
1 \text { ( } 25 \text { students; age } \\
14-15 \text { years) }\end{array}$ & $\begin{array}{l}\text { Oak Park High School } \\
\text { Achievement Component Grade: F } \\
\text { Percent of school Algebra } 1 \text { students } \\
\text { at Proficient or Above: } 22.1 \%\end{array}$ & $\begin{array}{l}\text { Oak Park School District } \\
\text { Enrollment: } 4,894 \\
\text { Percent minority students: } \\
\text { 57.8\%; Percent economically } \\
\text { disadvantaged students: } 99.9 \% \\
\end{array}$ \\
\hline $\begin{array}{l}\text { Lana (more } \\
\text { than } 20 \text { years } \\
\text { of experience) }\end{array}$ & $\begin{array}{l}\text { High School } \\
\text { Geometry (18 } \\
\text { students; age 15-16 } \\
\text { years) }\end{array}$ & $\begin{array}{l}\text { Woodcreek High School } \\
\text { Achievement Component Grade: D } \\
\text { Percent of school Geometry students } \\
\text { at Proficient or Above: } 25.8 \%\end{array}$ & $\begin{array}{l}\text { Woodcreek School District } \\
\text { Enrollment: } 3,732 \\
\text { Percent minority students: } \\
24.2 \% \text {; Percent economically } \\
\text { disadvantaged students: } 75.7 \% \\
\end{array}$ \\
\hline $\begin{array}{l}\text { Cora (more } \\
\text { than } 10 \text { years } \\
\text { of experience) }\end{array}$ & $\begin{array}{l}\text { High School Algebra } \\
2 \text { ( } 20 \text { students; age } \\
15-16 \text { years })\end{array}$ & $\begin{array}{l}\text { Woodcreek High School } \\
\text { Achievement Component Grade: D } \\
\text { No state Algebra } 2 \text { assessment } \\
\end{array}$ & $\begin{array}{l}\text { Woodcreek School District } \\
\text { (see Lana above) }\end{array}$ \\
\hline $\begin{array}{l}\text { Tami (more } \\
\text { than } 10 \text { years } \\
\text { of experience) }\end{array}$ & $\begin{array}{l}8^{\text {th }} \text {-Grade } \\
\text { Mathematics }(15 \\
\text { students; age } 13-14 \\
\text { years) }\end{array}$ & $\begin{array}{l}\text { Maple Hills PK- } 8 \\
\text { Achievement Component Grade: F } \\
\text { Percent of school } 8^{\text {th }} \text {-grade } \\
\text { mathematics students at Proficient } \\
\text { or Above: } 13.7 \%\end{array}$ & $\begin{array}{l}\text { Oak Park School District } \\
\text { (see Jeremy above) }\end{array}$ \\
\hline $\begin{array}{l}\text { Craig (more } \\
\text { than } 20 \text { years } \\
\text { of experience) }\end{array}$ & $\begin{array}{l}7^{\text {th }} \text {-Grade } \\
\text { Mathematics }(15 \\
\text { students; age } 12-13 \\
\text { years) }\end{array}$ & $\begin{array}{l}\text { Westview PK- } 8 \\
\text { Achievement Component Grade: F } \\
\text { Percent of school } 7^{\text {th }} \text {-grade } \\
\text { mathematics students at Proficient } \\
\text { or Above: } 32 \%\end{array}$ & $\begin{array}{l}\text { Oak Park School District } \\
\text { (see Jeremy above) }\end{array}$ \\
\hline
\end{tabular}

The information provided in Table 1 is for the 2016-2017 academic year. State data involving public school districts related to the information in Table 1 are as follows: average district enrollment: 1,695; state percent minority enrollment: $29.6 \%$; and, state percent economically disadvantaged student enrollment: $50.9 \%$. In addition, $56.0 \%$ of state teachers had more than 10 years of experience. Therefore, the two districts, four 
buildings, and four grade-levels/courses involved in teacher educator-embedded professional learning relate to state averages as follows:

- Each district is significantly larger (at least 2.2 times larger), in terms of student enrollment, than the state average.

- Woodcreek School District has a smaller percent minority enrollment than the state average (smaller by 5.4\%); whereas, Oak Park School District has a significantly larger percent minority enrollment (1.95 times larger than state average).

- Both districts have a significantly larger percent of economically disadvantaged students than the state average (at least 1.49 times larger). Oak Park School District, in particular, has almost 100\% percent economically disadvantaged student enrollment.

- Each of the five teachers are one of the $56.0 \%$ of state teachers with more than 10 years of classroom experience.

\section{Data}

Data consisted of material generated from teacher educator-embedding, participating teacher pre- and post-survey and assessments scores, and participating teachers' students' scores on state summative assessments. Specifically, data was comprised of: (1) video- and audio-recordings of and physical documents related to lesson co-planning sessions; (2) video- and audio-recordings of lesson implementations (i.e., coteaching); and (3) video- and audio-recordings of and physical documents related to reflections on student work and classroom instruction. In addition, teachers' pre- and post-survey and assessment scores involved: (1) Surveys of Enacted Curriculum (SEC) (Wisconsin Center for Education Research [WCER], 2018), (2) Reformed Teaching Observation Protocol (RTOP) (Piburn \& Sawada, 2000), and (3) project-developed content knowledge grade-level/course assessments. Analysis involved both quantitative and qualitative methods. Quantitative methods were employed to examine participating teachers' pre- and post-survey responses and pre- and postassessment scores. Qualitative methods serve to characterize several differences exhibited in tasks, activities, and classroom interactions as a result of mathematics teacher 'embedding.'

It must be noted that it took some time for participating teachers and the author (i.e., mathematics teacher educator) to become accustomed to working with the iterative instructional cycle utilized in the teacher educator-embedded model. For example, during the planning stage of the initial instruction cycle, two participating teachers (Jeremy and Craig) were intent to let the author take control of the lesson planning. In these instances, it was necessary for the author to make clear the lessons were to focus on what each teacher had identified as a goal or goals (during the goal-setting stage), relying on teachers' existing, familiar, and mandated documents. Furthermore, the author made clear that although lessons were to be co-planned, the author was relying on participating teachers' knowledge of their students' understandings and prior experiences. The most disparate experiences came during the implementation stage. A majority of participating teachers (i.e., Cora, Lana, and Craig) were challenged to let the author participate in instruction; these teachers exhibited hesitancy in sharing control in how lessons were managed with their students. The remaining two participating teachers (Jeremy and Tami) were the complete opposite, waiting for the author to 'take charge' of lessons. Over time, by the third lesson of the first instructional cycle for four teachers (Cora, Jeremy, Lana, and Craig), and the second lesson of the second cycle for the remaining teacher (Tami), the author and participating teachers had become comfortable co-planning, co-teaching, and co-reflecting.

Reformed Teaching Observation Protocol (RTOP). The Reformed Teaching Observation Protocol (RTOP) (Sawada et al., 2000) is an "observational instrument that can be used to assess the degree to which mathematics instruction is "reformed" (p. 1). The RTOP is criterion-referenced, is designed to be used by trained observers, and can be used from primary school through the university level. According to Sawada et al. (2000), "[O]bservers' judgments should not reflect a comparison with any other instructional setting than the one being evaluated" [authors' italics] (p. 1). In RTOP, 'reformed' teaching practices "reflect learning theory that posits that effective learning is active, learner-centered, inquiry-oriented, and prompts students to construct new concepts and conceptual systems by connecting new information to what they already know" (Amrein-Beardsley \& Osborn Popp, 2011, p. 6). The RTOP is a common and recommended instrument to use by mathematics and science partnership projects to assess teachers' classroom practices (Abt Associates, 2015). The degree to which a teacher's classroom practices are reformed is measured by her RTOP score, calculated by summing five subscales (Ebert-May et al., 2011): 
(1) lesson design and implementation, how well the instructor elicits students' prior knowledge, to what extent the instructor engages students and allows them to influence the focus and direction of the lesson; (2) propositional knowledge, how a teacher implements discipline-specific content; (3) procedural knowledge, the inquiry processes students use in the lesson; (4) communicative interactions, the proportion and variety of discussion that occurs among students and between the teacher and students; and (5) student-teacher relationship, attitudes of the teacher and students toward each other and the quality of their interactions. [authors' italics] (p. 552)

Participating teachers were observed and evaluated by the project's internal evaluator using the RTOP prior to their initial iteration of the instructional cycle (pre-embedding) and after their last iteration of the instructional cycle (post-embedding). Both evaluations occurred when teaching alone, without the mathematics teacher educator. The internal evaluator was a trained RTOP observer. The pre- and postembedding scores for Lana (high school Geometry) and Tami (8th-grade mathematics) are provided in Tables 2 and 3 , respectively.

Table 2. Lana's pre- and post-embedding RTOP scores

\begin{tabular}{lcc}
\hline Subscale & Pre-Embedding & Post-Embedding \\
\hline Lesson Design and Implementation & 6 & 11 \\
\hline Propositional Knowledge & 7 & 14 \\
\hline Procedural Knowledge & 7 & 10 \\
\hline Communicative Interactions & 11 & 10 \\
\hline Student-Teacher Relationship & 9 & 13 \\
\hline Total & 40 & 58 \\
\hline
\end{tabular}

Table 3. Tami's pre- and post-embedding RTOP scores

\begin{tabular}{lcc}
\hline Subscale & Pre-Embedding & Post-Embedding \\
\hline Lesson Design and Implementation & 6 & 8 \\
\hline Propositional Knowledge & 8 & 12 \\
\hline Procedural Knowledge & 7 & 10 \\
\hline Communicative Interactions & 5 & 10 \\
\hline Student-Teacher Relationship & 7 & 10 \\
\hline Total & 33 & 50 \\
\hline
\end{tabular}

As indicated in Table 2, Lana increased her RTOP score by 45.0\% through her experiences with the teacher educator-embedded professional learning model. Specific changes were exhibited in Lana's Lesson Design and Implementation, Propositional Knowledge, Procedural Knowledge, and Student-Teacher Relationship. As characterized by Ebert-May et al. (2011), Lana changed from RTOP Category II, represented as a teachercentered classroom with "lecture [and] some demonstration and minor student participation," (p. 553) to Category III, represented as a learner-centered classroom with "significant student engagement [and] some minds-on as well as hands-on involvement" (p. 553).

As indicated in Table 3, Tami increased her RTOP score by 51.5\% through her experiences with teacher educator-embedding. Specific changes were exhibited in all five of Lana's subscales: Lesson Design and Implementation, Propositional Knowledge, Procedural Knowledge, Commutative Interactions, and StudentTeacher Relationship. Similar to Lana, Tami changed from RTOP Category II, a teacher-centered classroom, to Category III, a learner-centered classroom (Ebert-May et al., 2011, p. 553). The mean subscale scores and total for the five participating teachers are illustrated in Table 4.

Table 4. Participating teachers' mean pre- and post-embedding RTOP scores

\begin{tabular}{lcc}
\hline Subscale & Pre-Embedding & Post-Embedding \\
\hline Lesson Design and Implementation & 6.8 & 9.2 \\
\hline Propositional Knowledge & 8.4 & 11.6 \\
\hline Procedural Knowledge & 7.0 & 8.4 \\
\hline Communicative Interactions & 6.4 & 10.2 \\
\hline Student-Teacher Relationship & 9.0 & 11.8 \\
\hline Total & 37.6 & 51.2 \\
\hline
\end{tabular}


As illustrated in Table 4, participating teachers' mean RTOP score increased by $36.2 \%$ through their experiences with teacher educator-embedding. The largest changes occurred in Communicative Interactions (59.4\% increase), Propositional Knowledge (38.1\% increase), and Lesson Design and Implementation (35.3\% increase).

Survey of Enacted Curriculum (SEC). According to the Wisconsin Center for Education Research (2018), "The Surveys of Enacted Curriculum (SEC) offer a practical, reliable set of data collection tools that support systematic reflection and dialogue around important curricular and school climate questions for teachers of mathematics" (para. 1). Furthermore, SEC survey data provide empirical "evidence-based data to inform curricular decisions at the classroom, building and district levels" (WCER, 2018, para. 1). The SEC (WCER, 2018) was a required evaluation measure for science and mathematics grant projects in the state in which this study was conducted. As part of the SEC, participating teachers were asked to indicate the topics they taught, the amount of time they spent on each topic, and the cognitive expectations they had for each topic. Results of teachers' responses can be graphed on a tile graph and compared to CCSSMs expectations as interpreted by the Wisconsin Center for Education Research. Figure 3 illustrates tiles graphs for the two middle grades teachers (Tami and Craig), pre- and post-embedding and CCSSM. The pre-embedding survey occurred prior to the goal-setting stage of the initial iterative cycle and the post-embedding survey occurred after the reflection stage of the last iterative cycle.

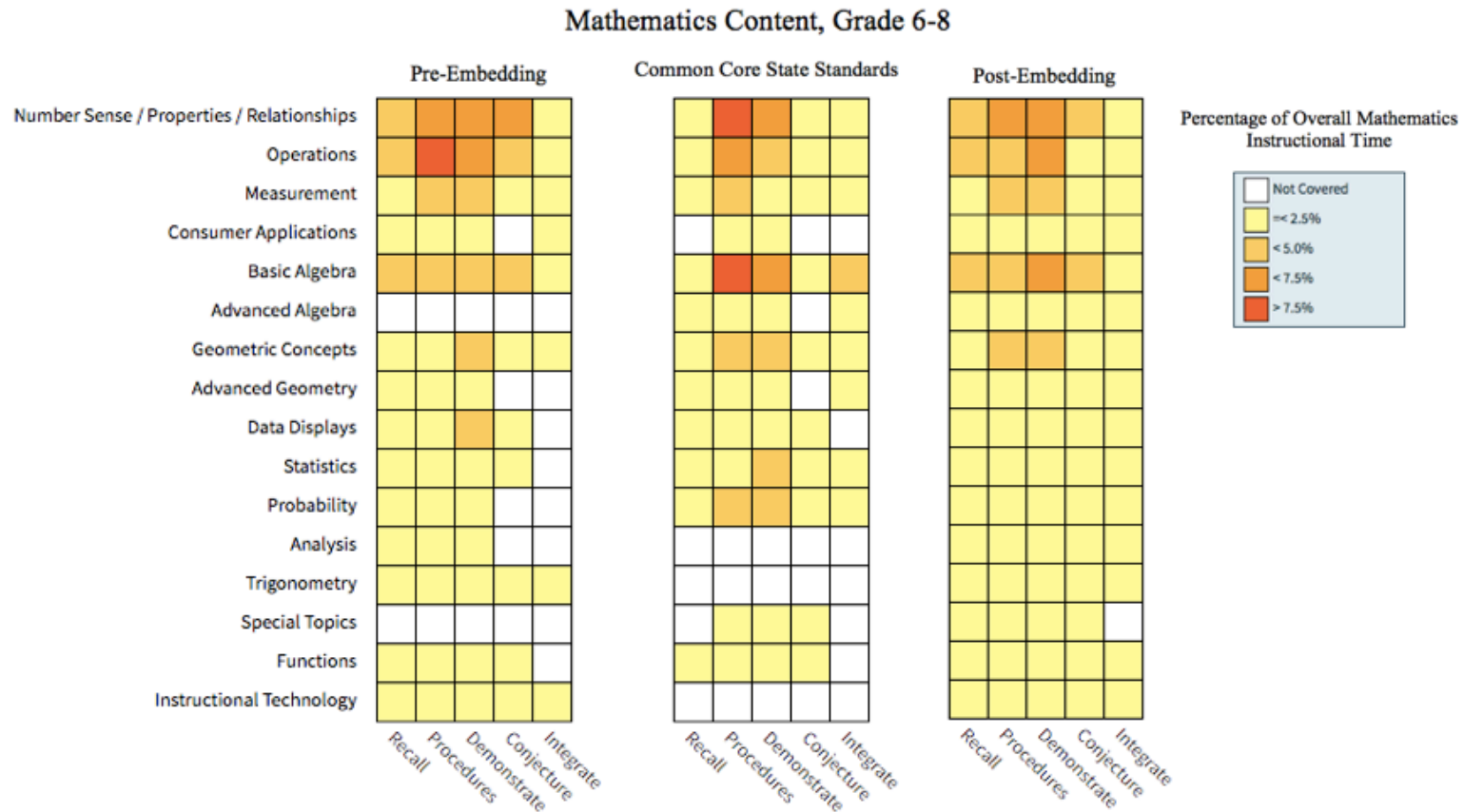

Figure 3. Grades 6-8 pre- and post-embedding alignment with CCSSM

SECs (CCSSO, 2009) coarse grain alignment can be used to quantify the alignment between a teacher's classroom instruction and CCSSM along the broadest mathematics topics. The coarse grain alignment between the 6th-8th-grade pre-embedding and CCSSM was 0.63 and between the post-embedding and CCSSM was 0.71 , a $12.7 \%$ increase in alignment. Figure 4 illustrates tiles graphs for the three secondary school teachers (Cora, Lana, and Jeremy) both pre- and post-embedding and CCSSM. 
Mathematics Content, Grade 9-12

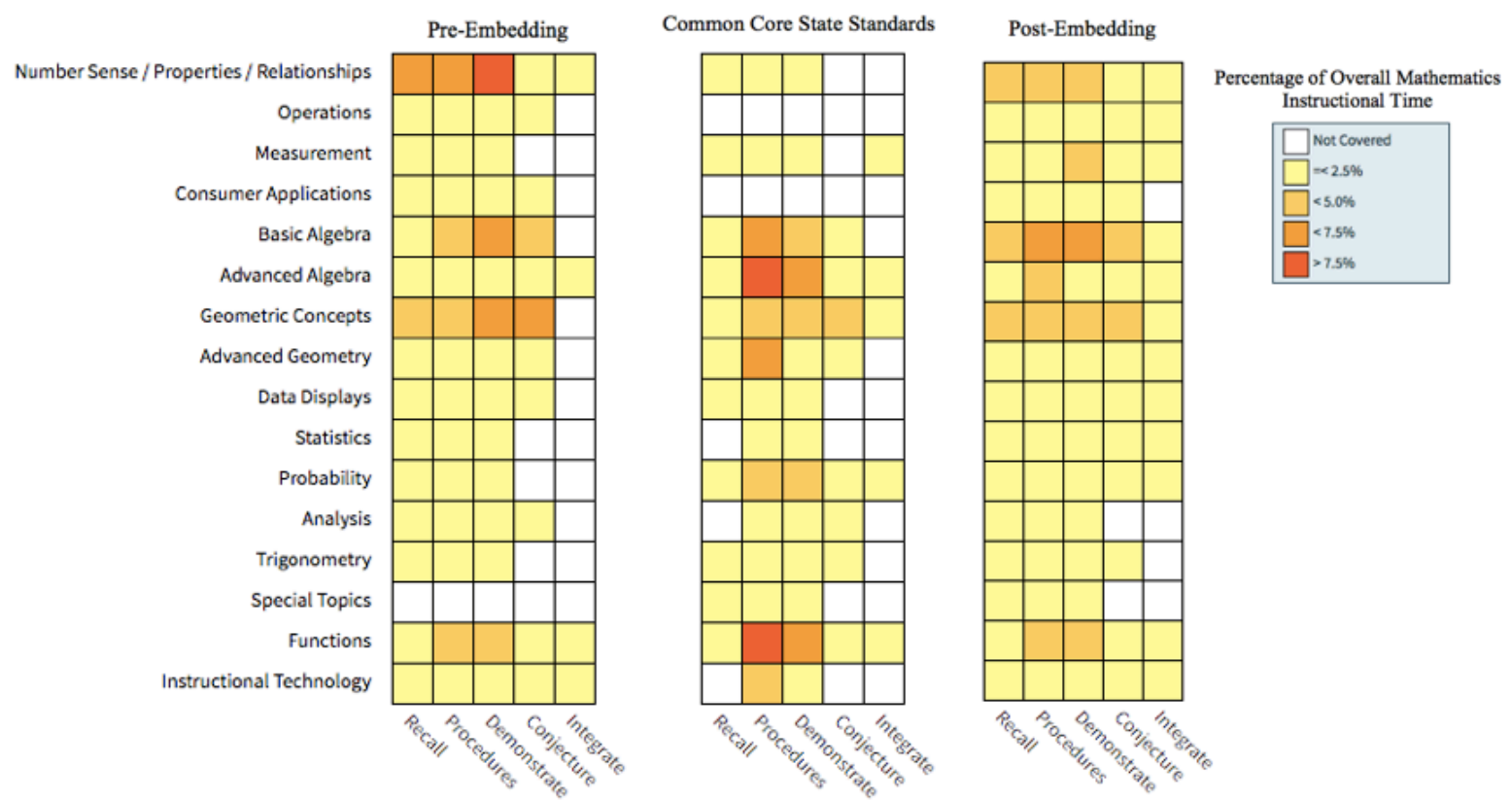

Figure 4. Grades 9-12 pre- and post-embedding alignment with CCSSM

As with the middle grades teachers, the pre-embedding survey for the secondary school teachers occurred prior to the goal-setting stage of the initial iterative cycle and the post-embedding survey occurred after the reflection stage of the last iterative cycle. The coarse grain alignment between the 9th-12th-grade preembedding and CCSSM was 0.49 and between the post-embedding and CCSSM was 0.56 , a $14.3 \%$ increase in alignment.

Teachers' content knowledge assessment. Participating teachers' knowledge of the mathematics content they teach was assessed at the beginning and end of the academic year with project-developed gradelevel or course assessments. As with the RTOP and SEC, pre-assessments were given prior to teachers starting their initial instructional cycle. Similarly, post-assessments were given after teachers had completed their final (fourth for three teachers; fifth for two teachers) instructional cycle. Assessments were developed collaboratively by the project team, which consisted of the author (project director and mathematics teacher educator), a professional facilitator (mathematics teacher educator), two university mathematics faculty, and two mathematics education doctoral students.

Assessments were designed to model the state summative assessments teachers' students were required to take and focused on CCSSMs major focus areas for each grade-level or course (Partnership for Assessment of Readiness for College and Careers [PARCC], 2017; Student Achievement Partners [SAP], n.d.). After examining several potential instruments for measuring teachers' content and pedagogical content knowledge (e.g., Hill, Schilling, \& Ball, 2004; Hill, Rowan, \& Ball, 2005; Krauss, Baumert, \& Blum, 2008; Swafford, Jones, Thornton, Stump, \& Miller, 1999), the project team determined that since none of these instruments were created or had been modified since adoption of the Common Core State Standards for Mathematics (NGA Center \& CCSSO, 2010), participating teachers would be best served by assessing their knowledge of the mathematical content and practice standards they actually teach—assessments aligned to CCSSM.

Assessment development was a multi-step process. The author (project director) first provided project personnel (i.e., professional development facilitator, graduate students) with major content areas as identified by Achieve the Core (SAP, n.d.) and PARCC (2017) for each grade level or high school course. Problems, tasks, and example assessment items were then harvested from various state-level and organizational sources (e.g., EngageNY, Inside Mathematics, Mathematics Assessment Project [MAP], CPALMS). Next, the entire project team collaborated to create assessment tasks and accompanying evaluation criteria based on the harvested items. Each grade-level or course assessment was not considered ready to implement until the entire sixmember project team agreed on the tasks, assessment length, and evaluation criteria. Participating teacher pre- and post-content knowledge assessment scores are provided in Table 5. 
Table 5. Participating teachers' pre- and post-content knowledge assessment scores

\begin{tabular}{ccccc}
\hline Teacher & Assessment & $\begin{array}{c}\text { Pre-Assessment } \\
\text { Score (out of 100) }\end{array}$ & $\begin{array}{c}\text { Post-Assessment } \\
\text { Score (out of 100) }\end{array}$ & $\begin{array}{c}\text { Percent Change in } \\
\text { Assessment Score }\end{array}$ \\
\hline Jeremy & High School Algebra 1 & 84.4 & 87.8 & $4.0 \%$ increase \\
\hline Cora & High School Algebra 2 & 68.8 & 85.0 & $23.6 \%$ increase \\
\hline Lana & High School Geometry & 66.7 & 83.3 & $24.9 \%$ increase \\
\hline Tami & $8^{\text {th }}$-Grade Mathematics & 90.0 & 100 & $11.1 \%$ increase \\
\hline Craig & $7^{\text {th }}$-Grade Mathematics & 83.3 & 100 & $20.0 \%$ increase \\
\hline & Average & 78.64 & 91.22 & $16.0 \%$ increase \\
\hline
\end{tabular}

As illustrated in Table 5, participating teachers' mean content knowledge score increased by $16.0 \%$ through their experiences with the teacher educator-embedded professional learning model. The two middle grades teachers' (Tami and Craig) mean content knowledge score increased by $15.4 \%$; whereas, the three secondary school teachers (Cora, Jeremy, and Lana) increased by $16.5 \%$.

Students' state summative assessment scores. Students of each participating teacher, except for Cora (Algebra 2 teacher) were required to take state summative assessments four to six weeks prior to the end of the academic year. Algebra 2 is not a course assessed at the state level. Although these assessments can evaluate student understandings and skills for any mathematics content standard in a given grade-level or course, each assessment places an emphasis on major content areas (PARCC 2017, SAP, n.d.). For each assessment, students receive a rating of 'Limited,' 'Basic,' 'Proficient,' 'Accelerated,' or 'Advanced.' The percent of students scoring at "Proficient or Above' for each teacher (other than Cora), each district, and the state are indicated in Table 6.

Table 6. Participating teachers' student state summative assessment scores

\begin{tabular}{ccccc}
\hline Teacher & Assessment & $\begin{array}{c}\text { Percent of Students } \\
\text { at Proficient or } \\
\text { Above (Teacher) }\end{array}$ & $\begin{array}{c}\text { Percent of Students } \\
\text { at Proficient or } \\
\text { Above (District) }\end{array}$ & $\begin{array}{c}\text { Percent of Students } \\
\text { at Proficient or } \\
\text { Above (State) }\end{array}$ \\
\hline Jeremy & High School Algebra 1 & 38 & 25 & 45.3 \\
\hline Lana & High School Geometry & 72 & 25.9 & 42.9 \\
\hline Tami & 8 $^{\text {th }}$-Grade Mathematics & 34 & 27.6 & 54.9 \\
\hline Craig & $7^{\text {th }}$-Grade Mathematics & 22 & 20.1 & 56.1 \\
\hline
\end{tabular}

As illustrated in Table 6, although all four teachers had more students scoring at 'Proficient' or levels above (i.e., 'Accelerated' and 'Advanced') on state summative assessments than their respective districts, only Lana had more 'Proficient or Above' students than the state average. Craig had $1.9 \%$ more students score 'Proficient or Above' than the district, but 34.1\% less students than the state average; whereas, Lana had $46.1 \%$ more students score 'Proficient or Above' than the district, and $29.1 \%$ more students than the state average.

Semi-structured interviews. At the conclusion of the project, the project's internal evaluator conducted one-on-one semi-structured interviews with participating teachers. Feedback, from the five mathematics teachers who engaged in teacher educator-embedding resulted in the following themes:

- Teachers increased their utilization of online resources (e.g., Desmos, GeoGebra, National Library of Virtual Manipulatives [NLVM], Illustrative Mathematics).

- Teachers increased differentiation in the classroom (e.g., adapting problems and tasks to meet student needs, utilizing multiple instructional strategies).

- There was increased collaboration with other teachers (both vertical and horizontal collaborationacross and within grade-levels or courses).

- There was increased student perseverance and engagement (e.g., students working harder and more engaged).

- Teachers made changes to their instruction (e.g., less lecture, deeper teacher questioning of student thinking and reasoning, more connections to real world and student interests, increased student collaboration).

- There was enhanced teacher content knowledge (e.g., ratio and proportional relationships, equations and expressions, understanding of fundamental ideas in geometry). 
In general, participating teachers also indicated an increased belief in their abilities to meet the mathematics needs of all students in their classroom and their students' capacities to engaged in more rigorous mathematics.

\section{ANALYSIS AND FINDINGS}

In this section, the author will discuss analyses of data from the previous section and characterize some of the differences exhibited in tasks, activities, classroom interactions, and planning and reflection sessions resulting from mathematics teacher educator-embedded professional learning. Such differences were emphasized during discussions with participating teachers about student work and video-stimulated reflection of classroom instruction in hopes participating teachers would productively reflect on: (1) their own and their students' content knowledge, (2) their instructional practices, (3) their self-efficacy, and (4) their students' capacities to engage in mathematical sense making, reasoning, modelling, generalizing, and communicating. Furthermore, findings will focus on students' mathematics knowledge, teachers' mathematics knowledge, teachers' instructional practices, author's attempts to motivate teachers to decenter, and author's efforts to generate cognitive residue of sufficient robustness to support teachers' productive reflection.

\section{Eighth Grade Geometry Lesson Planning Task}

The author worked with Tami to design, implement, and reflect on lessons covering, in part, the following content standard (NGA Center \& CCSSO, 2010): Describe the effect of dilations, translations, rotations, and reflections on two-dimensional figures using coordinates. Tami chose to focus on lessons that were cumulative in nature, coming near the end of a unit on transformational geometry. During the initial planning session, Tami shared a transformation task she assigned to small groups of students the previous year (Figure 5). Tami indicated her frustration with the level of uncertainty students had demonstrated when engaging with the task.

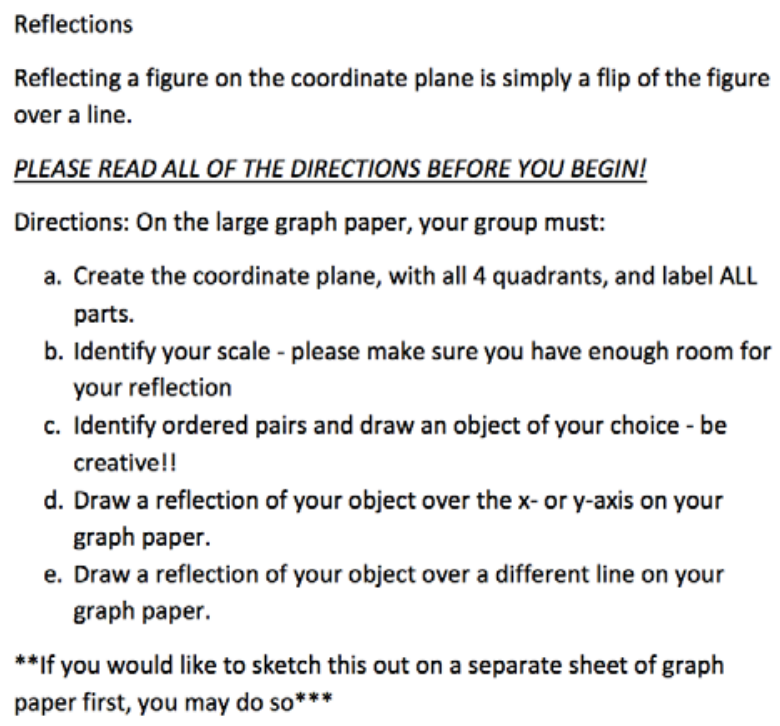

Figure 5. Tami's original reflection task

The author worked with Tami to articulate the meanings Tami intended for students to develop regarding reflections and whether Tami's current lessons anticipated similarity and congruence being defined in terms of transformations later in the academic year (coherence). Tami and the author developed several tasks for students to complete in small groups of two to three. Figure 6 illustrates one such task. 
(3) $\triangle \mathrm{ABC}$ and lines $\mathrm{y}=-\mathrm{x}$ and $\mathrm{y}=1$ are all shown on the coordinate grid below:

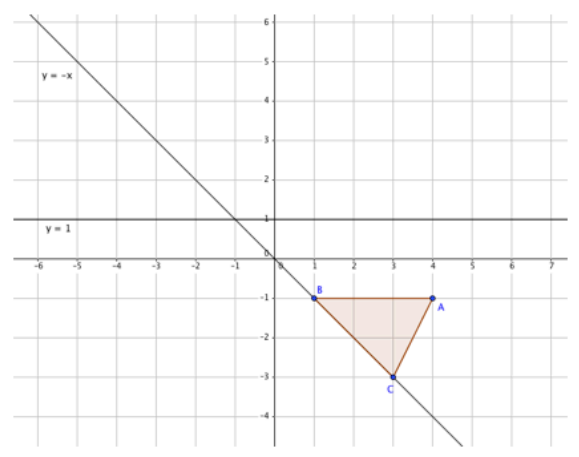

a) Reflect $\triangle A B C$ across the line $y=-x$ and then reflect the image over the line $y=1$. Draw the final image after these two reflections on the coordinate grid above.

b) Reflect $\triangle \mathrm{ABC}$ across the line $\mathrm{y}=1$ and then reflect the image over the line $y=-x$. Draw the final image after these two reflections on the coordinate grid above.

c) If you perform more than one reflection on $\triangle \mathrm{ABC}$ does it matter the order that you perform the reflections? Explain.

Figure 6. Tami and the author's reflection task

During video-stimulated reflection of classroom instruction (i.e., co-teaching), Tami indicated students were less frustrated and more engaged with the additional structure the new task provided. Tami felt her prior task (Figure 5) was too open-ended and did not provide students enough direction; she found herself doing too much of the work. The new task motivated students to think and reason at an appropriate level. In addition, by asking students to think about what they considered as triangle images being "the same," the task authentically anticipated future lessons (and discussions) regarding similarity and congruenceinstructional design Tami indicated she had not considered. These discussions were designed to motivate Tami to specifically reflect on her own and her students' content knowledge, her instructional practices, her students' self-efficacy, and her students' capacities to engage in mathematical sense making, reasoning, generalizing, and communicating.

\section{Ninth Grade Algebra 1 Classroom Instruction}

The author worked with Jeremy to design, implement, and reflect on lessons covering, in part, the following content standard (NGA Center \& CCSSO, 2010): Solve linear equations and inequalities in one variable, including equations with coefficients represented by letters. Jeremy chose to work on a lesson that came at the beginning of a unit on inequalities. Students in Jeremy's course were first year students at the district's lone high school (grades 9-12, ages 14-18 years). Students matriculate to this high school (Oak Park High School) from four different Grade K-8 (ages 5-6 to 13-14 years) buildings. Jeremy indicated students' mathematics experiences at the four Grade K-8 buildings were typically very different; state math achievement scores support this statement. The author worked with Jeremy to develop instruction that would motivate students to articulate their meanings for a variety of inequality problems-to get students' meanings out in the open as objects of thought and discussion.

This report will focus only on the initial such problems, and examine Jeremy and the author's implementation of the lesson and how the lesson's enactment (and the author and Jeremy's subsequent reflection) provided space for a robust discussion regarding meanings, instructional design, and students' mathematics capacities. At the beginning of class, Jeremy asked students, working individually, to graph four different inequalities and explain in writing what each inequality meant to them. The four inequality problems are shown in Figure 7. 


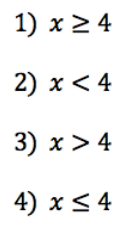

Figure 7. Jeremy's in-class inequality problems

After about five minutes, during which Jeremy walked around the room inspecting student work, Jeremy stated, "So, a lot of you are struggling a little bit with this . . I just wanted to see what you knew about inequalities."

Jeremy: What does that first inequality mean or what does it say?

Student 1: Greater than or equal to.

Jeremy: What does that mean? You know what the symbol is, you can write what it means, but what does that mean?

Student 2: The answer is greater than 4 or equal to 4 .

Jeremy: Give me some examples of what that's going to be.

Students: $\quad 7,18,9,4,11, \ldots$

Jeremy: 4, why 4 ?

Student 3: Because of the equal to.

Jeremy: How many are there?

Student 4: A lot.

Jeremy: Infinity or almost infinity?

Student 5: Infinity.

Jeremy: We're not going to get into that today.

[At this point the author picked up the second problem.]

Author: What about ' $x$ less than 4', what is that inequality telling us about ' $x$ '?

Student 1: That it's less than 4.

Author: But what is ' $x$ '? Can we be a little more specific about ' $x$ '?

Student 2: What do you mean?

Author: $\quad$ Can ' $x$ ' be a number like 2.5 or 11/12 or does it have to be an integer?

Student 3: What's an integer?

[After a period of time and several student-student and author-student interactions]

Author: $\quad$ Okay, so ' $x$ ' represents any real number less than 4 . . How many are there?

Student 4: A lot.

Author: Well, 'a lot' isn't very mathematically precise. Is $-200,000$ less than 4 ?

Student 5: Yes.

Author: $\quad$ Is a number less than $-200,000$ also less than 4 ?

Student 4: Yes.

Author: How could you find a way to determine a number less than $-200,000$ ?

Student 1: $\quad-400,000$.

Author: $\quad$ Okay, but we're looking for a process for finding a number less than $-200,000$.

Student 6: Subtract one from $-200,000$.

Author: Okay, and how could we then get a number smaller than $-200,000-1$ ?

Student 7: Subtract one again. 
During video-stimulated reflection of classroom instruction, Jeremy and the author discussed where each intended that students focus their thinking regarding the inequality problems. For Jeremy, the focus was first on the meaning of the inequality sign, and then the relationship between the variable, the inequality sign, and the constant. So, 'x < 5' indicated "less than"- "x's less than five", or "we're looking for x-values that are strictly less than five". For the author, the problem didn't make sense until he (and students) knew what type of number ' $x$ ' was (e.g., integer, rational). Furthermore, the author focused on mathematical precision, communication, reasoning, and generalizations (subtract one from the previous number to get another number that is also less than four). These discussions were designed to motivate Jeremy to specifically reflect on his own and his students' content knowledge, his instructional practices, his students' self-efficacy, and his students' capacities to engage in mathematical sense making, reasoning, generalizing, and communicating.

\section{Students' Mathematics Content Knowledge}

Student content knowledge data available for quantitative analysis was limited to state assessment scores. Table 6 illustrates students state summative assessment scores for each participating teacher (except for Cora) at the teacher, district, and state levels. Table 7 highlights results from two proportion z-tests to compare the percent (or proportion) of students 'Proficient or Above' between the teacher and district levels, and the teacher and state levels.

Table 7. Two proportion z-test comparisons between student state summative assessment scores at teacher, district, and state levels

\begin{tabular}{|c|c|c|c|c|c|c|}
\hline $\begin{array}{c}\text { Teacher / } \\
\text { Assessment }\end{array}$ & $\begin{array}{c}\text { Percent 'Proficient } \\
\text { or Above' (district } \\
\text { / state) }\end{array}$ & $\begin{array}{c}\text { Sample Size } \\
\text { (district / } \\
\text { state) } \\
\end{array}$ & $\begin{array}{c}\text { Percent } \\
\text { 'Proficient or } \\
\text { Above' (class) } \\
\end{array}$ & $\begin{array}{l}\text { Sample Size } \\
\text { (class) }\end{array}$ & $\begin{array}{c}\mathrm{Z} \\
\text { score }\end{array}$ & $\begin{array}{c}\text { P-value ( } \alpha= \\
\text { 0. 05, one-sided } \\
\text { hypothesis) }\end{array}$ \\
\hline $\begin{array}{c}\text { Jeremy / } \\
\text { Algebra } 1\end{array}$ & 25 (district) & 545 (district) & 38 & 25 & 1.46 & $p=0.073$ \\
\hline $\begin{array}{l}\text { Jeremy / } \\
\text { Algebra } 1\end{array}$ & 45.3 (state) & $\begin{array}{c}168,285 \\
\text { (state) }\end{array}$ & 38 & 25 & -0.73 & $\mathrm{p}=0.232$ \\
\hline $\begin{array}{c}\text { Lana / } \\
\text { Geometry }\end{array}$ & 25.9 (district) & 304 (district) & 72 & 18 & 4.21 & $\mathrm{p}<0.0001$ \\
\hline $\begin{array}{c}\text { Lana / } \\
\text { Geometry }\end{array}$ & 42.9 (state) & $\begin{array}{c}140,054 \\
\text { (state) }\end{array}$ & 72 & 18 & 2.49 & $p=0.006$ \\
\hline $\begin{array}{l}\text { Tami } / 8^{\text {th }} \text { - } \\
\text { grade }\end{array}$ & 27.6 (district) & 278 (district) & 34 & 15 & 0.54 & $\mathrm{p}=0.295$ \\
\hline $\begin{array}{l}\text { Tami / } 8^{\text {th }} \\
\text { grade }\end{array}$ & 54.9 (state) & $\begin{array}{c}100,536 \\
\text { (state) }\end{array}$ & 34 & 15 & -1.63 & $p=0.052$ \\
\hline $\begin{array}{l}\text { Craig / } 7^{\text {th }} \\
\text { grade }\end{array}$ & 20.1 (district) & 288 (district) & 22 & 15 & 0.18 & $\mathrm{p}=0.429$ \\
\hline $\begin{array}{l}\text { Craig / } 7^{\text {th }} \\
\text { grade }\end{array}$ & 56.1 (state) & $\begin{array}{c}125,336 \\
\text { (state) }\end{array}$ & 22 & 15 & -2.66 & $\mathrm{p}=0.004$ \\
\hline
\end{tabular}

As illustrated in Table 7, the only statistically significant comparisons were: (1) the percent of students scoring 'Proficient or Above' in Lana's Geometry class was significantly larger than all other Geometry student in her district; (2) the percent of students scoring 'Proficient or Above' in Lana's Geometry class was significantly larger than all other Geometry students in the state; and (3) the percent of students scoring 'Proficient or Above' in Craig's 8th-grade mathematics class was significantly less than all other 8th-grade mathematics students in the state. Therefore, based strictly on state summative assessment data, the teacher educator-embedded professional learning model did not support students of participating teachers to score significantly different on state summative assessments than students of non-participating teachers. Although state summative assessments failed to provide evidence of increased student achievement, participating teachers indicated (during one-on-one semi-structured interviews at the project's conclusion) their students were: engaging in and exhibiting more frequent and deeper thinking and reasoning; and, exhibiting increased perseverance, motivation, collaboration, and capacities to take ownership of their own learning.

\section{Teachers' Mathematics Content Knowledge}

Teacher content knowledge data available for quantitative analysis was limited to the project-developed content knowledge assessment scores. As illustrated in Table 5, each participating teacher increased their score on the respective content knowledge assessments. A paired-samples t-test was conducted to compare the 
participating teachers' mean content knowledge pre-assessment and post-assessment scores. There was a significant difference in participating teachers' scores on the pre-assessment $(\mathrm{M}=78.6, \mathrm{SD}=10.3)$ and postassessment $(\mathrm{M}=91.2, \mathrm{SD}=8.2) ; \mathrm{t}(4)=-4.80, \mathrm{p}=0.009$. Therefore, classroom teachers engaged in the teacher educator-embedded professional learning model scored significantly higher on the project-developed content knowledge post-assessment than they did on the pre-assessment. It must be re-stated the pre-assessment was given at the beginning of the academic year and the post-assessment was given at the end of the academic year. As such, participating teachers had engaged with their respective grade-level or course content throughout the academic year (potentially impacting their post-assessment scores), as opposed to spending a significant portion of the summer recess - at most 10 weeks — not as engaged with their content (potentially impacting their pre-assessment scores).

In addition to teachers' scores on the project-developed content knowledge assessment, teachers described enhancement in their content knowledge during one-on-one semi-structured interviews at the project's conclusion. Specifically, teachers asserted their knowledge had been enhanced in relation to: ratio and proportional relationships (Craig), equations, expressions, and inequalities (e.g., structure) (Cora, Jeremy, and Tami), probabilities of compound events (Lana), and understanding of fundamental ideas in geometry (e.g., similarity, congruence) (Lana). Finally, through interactions with teachers during the four or five iterative instructional cycles, the project team identified a clear increase in teachers' understanding and utilization of tasks with realistic contexts in several domains (e.g., expressions and equations, relationships in geometry); a realistic context is defined as "a situation [that] can be imagined - a student could place themselves in the context” (Institute for Advanced Study/Park City Mathematics Institute, 2011, p. 4).

\section{Teachers' Instructional Practices}

Participating teachers' instructional practices were examined in several ways. Data from the Surveys of Enacted Curriculum (SEC), Figures 3 and 4, indicated the curriculum participating teachers enacted in their classrooms was more aligned with the Common Core State Standards for Mathematics after having engaged in the teacher educator-embedded professional learning model than before. For example, the coarse grain alignment between Tami and Craig's conceptions of the enacted curriculum and CCSSM (grades 6-8) was 0.63 pre-embedding and 0.71 post-embedding. In particular, post-survey teacher responses indicated an increase in the following broad topics along "five categories of cognitive expectations for students (indicated by vertical lines)" (CCSSO, 2005, p. 17)—recall, procedures, demonstrate, conjecture, integrate: advanced algebra was fully covered as opposed to not being covered at all; advanced geometry (integrate) was covered; and, probability (conjecture and integrate) was covered. Similarly, the coarse grain alignment between Cora, Jeremy, and Lana's conceptions of the enacted curriculum and CCSSM (grades 9-12) was 0.49 pre-embedding and 0.56 post-embedding. In particular, post-survey teacher responses indicated: geometric concepts (integrate) were covered; probability (conjecture and integrate) was covered; and trigonometry (conjecture) was covered.

Similar to teachers' content knowledge assessments, data for the pre-embedding SEC were obtained at the beginning of the academic year and at the end of the academic year for the post-embedding SEC. As such, participating teachers had engaged with their respective grade-level or course content throughout the academic year (potentially impacting their post-embedding coarse grain alignment), as opposed to having spent a significant portion of the summer recess not as engaged (potentially impacting their pre-embedding coarse grain alignment). Furthermore, SEC tile graphs (as displayed in Figures 3 and 4) were not available for comparison between individual teacher's views of the content they conceived of enacting and CCSSM (e.g., between Tami's conception of 8th grade mathematics and the 8th-grade CCSSM standards). As such, this also made it impossible to compare tile graphs for only 7th and 8th-grade CCSSSM and Tami and Craig's conceptions of 7th and 8th grade mathematics (i.e., it was necessary to include Grade 6), and Algebra 1, Geometry, and Algebra 2 CCSSM and Cora, Jeremy and Lana's conceptions of Algebra 1, Geometry, and Algebra 2 (it was necessary to include all of grades 9-12).

RTOP data (see Table 4) provides a clearer example of how teachers' classroom instruction changed as a result of their participation in teacher educator-embedded professional learning model. A paired-samples ttest was conducted to compare the participating teachers' mean pre- and post-embedding RTOP subscale scores. There was a significant difference in participating teachers' mean subscale scores on the pre-embedding RTOP $(\mathrm{M}=7.5, \mathrm{SD}=1.1)$ and post-embedding RTOP $(\mathrm{M}=10.2, \mathrm{SD}=1.5) ; \mathrm{t}(4)=-6.75, \mathrm{p}=0.03$. Therefore, classroom teachers engaged in teacher educator-embedding had significantly higher mean subscale RTOP scores post-embedding than pre-embedding. 
Finally, teachers described enhancements to their instruction during one-on-one semi-structured interviews at the project's conclusion. Specifically, teachers asserted their instruction had been productively transformed in relation to: increased utilization of online resources (e.g., Desmos, Illustrative Mathematics); increased differentiation of materials and instruction (e.g., adapting problems and tasks to meet student needs); less frequent lectures, increased student collaboration, and deeper teacher questioning of student thinking and reasoning.

\section{CONCLUSION}

Standardized year-end student summative assessments have placed enormous stress on mathematics teachers in the United States. Not only are teacher evaluations impacted by their students' achievement on state summative assessments, such assessments also require teachers attempt to help their students develop a full year's worth of mathematics understandings, skills, and ways of thinking and reasoning in about threefourths of an academic year-state summative assessments are given four to seven weeks prior to the end of the school year. Teachers involved in the teacher educator-embedded professional learning model described here, indicated participation reduced their feelings of constraint due to district and state demands. Rather than feeling the need to rush through content and focus on skills and procedures, the collaborative nature of embedded professional learning allowed teachers to focus on student understanding, mathematics coherence, and productive discourse.

Observations of lessons planned and enacted without the author (i.e., embedded teacher educator), made four months after the end of the project, indicated participating teachers continued to focus on rigorous mathematics that more frequently engaged their students in mathematical sense making, reasoning, modelling, generalizing, and communication than prior to their teacher educator-embedding experiences. The author posits teachers' continuation of such enhanced practices derives not only from transformed ways of operating, but also from their focus on the didactic triad (Thompson, 2009; Valero, 2009). Valero (2009) asserts the didactic triad is "constituted by the relationships between mathematics, the teacher and the student" (p. LX). For Valero (2009), "Mathematics education research, as characterized . . . with a focus on the didactic triad, has tended to focus so much in individual mathematical thinking, reasoning and cognition that the 'social' dimension was almost non-existing" (p. LXV). Thompson's (2009) characterization of the didactic triad conceptualizes classroom practices to incorporate conversations in which the teacher and her students "speak in ways that make their meanings clear to others in the conversation; they speak about ideas and ways of thinking" (Thompson, 2006, para. 1). According to Thompson (2009), the didactic triad, is a representation of the interrelationships among: (1) creating a clear statement of the mathematical ideas and ways of thinking one intends that students learn from instruction, (2) creating tasks and materials designed to support students' learning in the context of instruction, and (3) the design of instruction aimed at supporting students' learning while engaging with tasks and materials designed to support that learning. Therefore, the didactic triad, when taken as an object of discussion and reflection, provides a means of support that re-orients teachers productively as they design instruction, and emphasizes the connections among three aspects of instruction: learning goals-understandings and/or ways of thinking the teacher intends for their students to develop; tasks/materials-tasks, activities, and materials the teacher chooses, creates, or modifies to support the development of the intended ideas; and, teaching—choreographing activities and conversations about those activities in a manner that enhances the likelihood that students develop the intended understandings and/or ways of thinking.

Although data generated from teachers' engagements with the teacher educator-embedded professional learning model allowed for minimal quantitative analysis, restrictions on data obtained from the Surveys of Enacted Curriculum, Reformed Teaching Observation Protocol, and project-developed teacher content assessment, as described earlier, limited the robustness of analyses. As such, future explorations of teacher educator-embedding would benefit from the type of quantitative analysis that could be provided by instruments such as the Mathematics Classroom Observation Protocol for Practices (Gleason, Livers, \& Zelkowski, 2017). Finally, a significant challenge to the teacher educator-embedded professional learning model is the notion of 'scaling-up,' in the sense of expanding the number of teachers, schools, and districts engaging in the intervention. This challenge (or limitation) could potentially be addressed by using postembedded teachers in the role of 'teacher educator' in the model-although this would subsequently cause conflicts in scheduling and workforce that would need to be addressed. 


\section{Disclosure statement}

No potential conflict of interest was reported by the authors.

\section{Notes on contributors}

Scott A. Courtney - Kent State University, USA.

\section{REFERENCES}

Abt Associates Inc. (2015, March). A guide for reporting on evaluations for the U.S. Department of Education Mathematics and Science Partnerships (MSP): A user-friendly guide for MSP project officials and evaluators. Cambridge, MA: Abt Associates.

Achieve the Core. (n.d.). Mathematics: Focus by grade level. New York, NY: Student Achievement Partners. Retrieved from https://achievethecore.org/category/774/mathematics-focus-by-grade-level

Amrein-Beardsley A., Osborn Popp S. E. (2012). Peer observations among faculty in a college of education: investigating the summative and formative uses of the Reformed Teaching Observation Protocol (RTOP). Educational Assessment, Evaluation and Accountability, 24, 5-24. https://doi.org/10.1007/s11092-011-9135-1

Bacharach, N., Heck, T. W., \& Dahlberg, K. (2010). Changing the face of student teaching through co- teaching. Action in Teacher Education, 32(1), 3-14. https://doi.org/10.1080/01626620.2010.10463538

Bruce, C. D., Esmonde, I., Ross, J., Dookie, L., \& Beatty, R. (2010). The effects of sustained classroomembedded teacher professional learning on teacher efficacy and related student achievement. Teaching and Teacher Education, 26(8), 1598-1608. https://doi.org/10.1016/j.tate.2010.06.011

Clarke, D. (1994). Ten key principles from research for the professional development of mathematics teachers. In D. B. Aichele and A. F. Coxford (Eds.), Professional Development for Teachers of Mathematics, 1994 Yearbook (pp. 37-48), Reston, VA: National Council of Teachers of Mathematics.

Cook, L. \& Friend, M. (1995). Co-Teaching: Guidelines for creating effective practices. Focus on Exceptional Children, 28(3), 1-16.

Council of Chief State School Officers (CCSSO). (2005). Surveys of enacted curriculum: A guide for SEC state and local coordinators. Washington, DC: Author.

Council of Chief State School Officers (CCSSO). (2009). SEC self-guided tour of data charts: Introduction to data reported through the surveys of enacted curriculum online report generator. Washington, DC: Author.

Courtney, S. (2017). What teachers understand of model lessons. Cogent Education, 4(1), 1-23.

Covey, S. R. (2004). The seven habits of highly effective people: Powerful lessons in personal change. New York: Free Press/Simon \& Schuster.

Darling-Hammond, L, \& McLaughlin, M. W. (1995). Policies that support professional development in an era of reform. Phi Delta Kappan, 76(8), 597-604.

Dieker, L. A., \& Murawski, W. W. (2003). Co-teaching at the secondary level: Unique issues, current trends, and suggestions for success. The High School Journal, 86(4), 1-13. https://doi.org/10.1353/hsj.2003.0007

Ebert-May D., Derting T. L., Hodder J., Momsen J. L., Long T. M., Jardeleza S. E. (2011). What we say is not what we do: Effective evaluation of faculty professional development programs. Bioscience, 61(7), 550558. https://doi.org/10.1525/bio.2011.61.7.9

Fernandez, C., Cannon, J., \& Chokshi, S. (2003). A U.S.-Japan lesson study collaborative reveals critical lenses for examining practice. Teaching and Teacher Education, 19, 171-185. https://doi.org/10.1016/S0742051X(02)00102-6

Florida State University. (2017). CPALMS. Tallahassee, FL: Author. Retrieved from http://www.cpalms.org/Public/

Friend, M. (2008). Co-teaching: A simple solution that isn't simple after all. Journal of Curriculum and Instruction, 2(2), 9-19. https://doi.org/10.3776/joci.2008.v2n2p9-19

Gleason, J., Livers, S., \& Zelkowski, J. (2017). Mathematics Classroom Observation Protocol for Practices (MCOP2): A validation study. Investigations in Mathematics Learning, 9, 1-19. https://doi.org/10.1080/19477503.2017.1308697 
Guskey, T. R., \& Yoon, K. S. (2009). What works in professional development? Phi Delta Kappan, 90(7), 495500. https://doi.org/10.1177/003172170909000709

Hill, H. C., Rowan, B., \& Ball, D. L. (2005). Effects of teachers' mathematics knowledge for teaching on student achievement. American Educational Research Journal, 42(2), 371-406. https://doi.org/10.3102/00028312042002371

Hill, H. C., Schilling, S. G., \& Ball, D. L. (2004). Developing measures of teachers' mathematics knowledge for teaching. Elementary School Journal, 105(1), 11-30. https://doi.org/10.1086/428763

Idol, L. (2006). Toward inclusion of special education students in general education: A program evaluation of eight schools. Remedial and Special Education, 27(2), https://doi.org/10.1177/07419325060270020601

Ingvarson, L. (2005). Getting professional development right. ACER Annual Conference Proceedings 2005, Using Data to Support Student Learning. Melbourne, Australia: ACER Press.

Inside Mathematics. (2017). Common core state standards for mathematical content. Austin, TX: The Charles A. Dana Center, The University of Texas at Austin. Retrieved from http://www.insidemathematics.org/

Institute for Advanced Study/Park City Mathematics Institute. (2011). Resources to supplement rubric implementing mathematical practices. Princeton, NJ: Author, Secondary School Teachers Program.

Krauss, S., Baumert, J., \& Blum, W. (2008). Secondary mathematics teachers' pedagogical content knowledge and content knowledge: validation of the COACTIV constructs. ZDM, 40(5), 873-892. https://doi.org/10.1007/s11858-008-0141-9

Lewis, C. (2002). Lesson study: A handbook of teacher-led instructional change. Philadelphia, PA: Research for Better Schools.

Lewis, C. C., Perry, R. R., \& Hurd, J. (2009). Improving mathematics instruction through lesson study: A theoretical model and North American case. Journal of Mathematics Teacher Education, 12(4), 285304. https://doi.org/10.1007/s10857-009-9102-7

Lewis, C., Perry, R., \& Hurd, J. (2004, February). A deeper look at lesson study. Educational Leadership, 61(5), $18-22$.

Lewis, C., Perry, R., Hurd, J., \& O’Connell, M. P. (2006). Lesson study comes of age in North America. Phi Delta Kappan, 88(4), 273-281. https://doi.org/10.1177/003172170608800406

Loucks-Horsley, S., Stiles, K. E., Mundry, S., Love, N., \& Hewson, P. W. (2010). Designing professional development for teachers of science and mathematics (3rd ed.). Thousand Oaks, CA: Corwin.

Lyle, J. (2003). Stimulated recall: A report on its use in naturalistic research. British Educational Research Journal, 29(6), 861-878. https://doi.org/10.1080/0141192032000137349

Mathematics Assessment Project. (2015). Common core state standards. Oakland: CA: Shell Center for Mathematics Education, University of Nottingham (Shell Center), the University of California, Berkeley (UC Berkeley). Retrieved from http://map.mathshell.org/materials/index.php

National Governors Association Center for Best Practices \& Council of Chief State School Officers (NGA Center \& CCSSO) (2010). Common core state standards for mathematics. Washington, DC: Authors.

Nebraska State Board of Education. (2015). Nebraska's college and career ready standards for mathematics. Lincoln, NE: Nebraska Department of Education.

New York State Education Department. (n.d.). EngageNY. Albany, NY: Author. Retrieved from https://www.engageny.org/

Nguyen, N. T., McFadden, A., Tangen, D., \& Beutel, D. (2013). Video-stimulated recall interviews in qualitative research. Paper presented at the AARE Annual Conference, Adelaide, Australia.

Partnership for Assessment of Readiness for College and Careers (PARCC). (2017, November). PARCC model content frameworks: Mathematics, Grades 3-11 (Version 5.0). Austin, TX: New Meridian Corporation.

Perry, R. R., \& Lewis, C. C. (2009). What is successful adaptation of Lesson Study in the U.S.? Journal of Educational Change, 10(4), 365-391. https://doi.org/10.1007/s10833-008-9069-7

Piaget, J. (1962). Comments on Vygotsky's critical remarks concerning The Language and Thought of the Child, and Judgment and Reasoning in the Child (A. Parsons, Trans., \& E. Hanfmann \& G. Vakar, Eds.). Cambridge, MA: M.I.T. Press.

Piburn, M., \& Sawada, D. (2000). Reformed teaching observation protocol (RTOP): Reference manual (ACET Tech. Rep. No. IN00-3). Tempe: Arizona Collaborative for Excellence in the Preparation of Teachers, Arizona State University. 
Rea, P. J., McLaughlin, V. L., \& Walther-Thomas, C. (2002). Outcomes for students with learning disabilities in inclusive and pullout programs. Exceptional Children, 68(2), 203-222. https://doi.org/10.1177/001440290206800204

Rice, D., \& Zigmond, N. (2000). Co-teaching in secondary schools: Teacher reports of developments in Australian and American classrooms. Learning Disabilities Research \& Practice, 15(4), 190-197. https://doi.org/10.1207/SLDRP1504_3

Rosenbaum, D. A. (1972). The theory of cognitive residues: A new view of fantasy. Psychological Review, 79(6), 471-486. https://doi.org/10.1037/h0033548

Rowe, V. (2009). Using video-stimulated recall as a basis for interviews: Some experiences from the field. Music Education Research, 11(4), 425-437. https://doi.org/10.1080/14613800903390766

Salomon, G., Globerson, T., \& Guterman, E. (1989). The computer as a zone of proximal development: Internalizing reading-related metacognition from a reading partner. Journal of Educational Psychology, 81(4), 620-627. https://doi.org/10.1037/0022-0663.81.4.620

Salomon, G., Perkins, D. N., \& Globerson, T. (1991). Partners in cognition: Extending human intelligence with

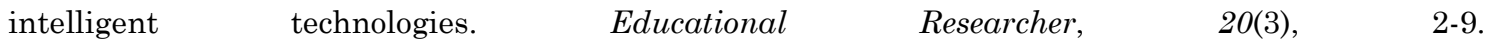
https://doi.org/10.3102/0013189X020003002

Sawada, D., Piburn, M., Turley, J., Falconer, K., Benford R., Bloom, I., \& Judson, E. (2000) Reformed teaching observation protocol (RTOP) training guide (ACET Tech. Rep. No. IN00-2). Tempe: Arizona Collaborative for Excellence in the Preparation of Teachers, Arizona State University.

Silverman, J. (2005). Examining the relationships between teachers' understandings of mathematics content and their developing pedagogy. Unpublished doctoral dissertation, Vanderbilt University.

Silverman, J., \& Thompson, P. W. (2008). Toward a framework for the development of mathematical knowledge for teaching. Journal of Mathematics Teacher Education, 11(6), 499-511. https://oi.org/10.1007/s10857-008-9089-5

Simon, M. (1995). Reconstructing mathematics pedagogy from a constructivist perspective. Journal for Research in Mathematics Education, 26(2), 114-145. https://doi.org/10.2307/749205

Steffe, L. P., \& Thompson, P. W. (2000). Interaction or intersubjectivity? A reply to Lerman. Journal for Research in Mathematics Education, 31(2), 191-209. https://doi.org/10.2307/749751

Swafford, J. O., Jones, G. A., Thornton, C. A., Stump, S. L., \& Miller, D. R. (1999). The impact on instructional practice of a teacher change model. Journal of Research and Development in Education, 32(2), 69-82.

Sztajn, P., Marrongelle, K, \& Smith, P. (2011). Supporting implementation of the common core state standards for mathematics: Recommendations for professional development. Raleigh, NC: College of Education, North Carolina State University.

Taylor, A. R., Anderson, S., Meyer, K., Wagner, M. K., \& West, C. (2005). Lesson study: A professional development model for mathematics reform. Rural Educator, 26(2), 17-22.

Thompson, P. W. (2006). What makes a conversation conceptual? Retrieved from http://tpc2.net/Courses/Func1F05/ConceptConv.html

Thompson, P. W. (2009, August). The didactic triad in mathematics teacher professional development. Invited presentation given at the University of Michigan College of Education, Ann Arbor, MI.

Thompson, P. W. (2013). In the Absence of Meaning. In K. Leatham (Ed.), Vital Directions for Research in Mathematics Education (pp. 57-93), New York, NY: Springer, 2013. https://doi.org/10.1007/978-1-46146977-3_4

Thompson, P. W. (2016). Researching mathematical meanings for teaching. In English, L., \& Kirshner, D. (Eds.), Handbook of International Research in Mathematics Education (pp. 435-461). London: Taylor and Francis.

Valero, P. (2010). Mathematics education as a network of social practices. In V. Durand-Guerier, S. SouryLavergne, \& F. Arzarello (Eds.), Proceedings of the Sixth Congress of the European Society for Research in Mathematics Education (pp. LIV-LXXX). Lyon, France: Institut National de Recherche Pedagogique.

Walsh, J. M. (2012). Co-teaching as a school system strategy for continuous improvement. Preventing School Failure, 56(1), 29-36. https://doi.org/10.1080/1045988X.2011.555792

Webster-Wright, A. (2009). Reframing professional development through understanding authentic professional learning. Review of Educational Research, 79(2), 702-739. https://doi.org/10.3102/0034654308330970 
Wiggins, G., \& McTighe, J. (2005). Understanding by design (2nd ed.). Alexandria, VA: Association for Supervision and Curriculum Development.

Wisconsin Center for Education Research (WCER). (2018). Surveys of Enacted Curriculum (SEC). Madison, WI: WCER, School of Education, University of Wisconsin-Madison.

http://www.iejme.com 